\title{
PEMMALI: \\ METODE DAKWAH LELUHUR BUGIS MAKASSAR
}

\author{
ZAENAL ABIDIN*, SABRI SAMIN, MOH. SABRI AR. \\ Universitas Islam Negeri (UIN) Alauddin Makassar \\ Email: zet46id@uin-alauddin.ac.id
}

\begin{abstract}
:
This article examines the pemmali as a method of da'wah by Bugis and Makassar ancestors in maintaining the noble values formulated in the cultural system. This study with the dawah approach found that the Bugis and Makassar people always maintained the most fundamental values, namely siri'. This value is at the core of a cultural system called pangadereng. Implementation of Pangangadereng is always maintained and controlled through paseng (warning / tazkirah) or (message / wasiyah) and pemmali or prohibition and prevention. Paseng has a role in directing the implementation of the values of Pangangadereng, while pemmali as an effort to prevent violations against pangngadereng. Paseng in the science of da'wah aims to amar ma'ruf, while pemmali is directed at the nahi munkar. Amar ma'ruf and nahi munkar in the science of da'wah are part of the function of dakwah activities that must be realized. There are various ways of carrying out these functions, including the tanzir methods. The tanzir which means a warning against this threat was taken by the ancestors of the Bugis and Makassar people with pemmali
\end{abstract}

Keywords: Pemmali, dakwah method, tanzīr, nāhi munkar

\section{PENDAHULUAN}

Bugis dan Makassar merupakan dua suku terbesar yang mendiami pulau Sulawesi Selatan. Kedua suku ini termasuk rumpun bangsa Melayu, ${ }^{1}$ dan sepanjang sejarahnya, telah menyebar ke berbagai daerah di Indonesia bahkan berdiaspora ke mancanegara.

Manusia Bugis Makassar dalam eksistensinya sebagai makhluk hidup, terikat oleh kebutuhan dan terdorong untuk senantiasa memenuhi kebutuhannya, yang dibagi oleh Abraham Moslow (1908-1970) secara hierarki, mulai dari yang paling mendasar hingga yang paling tinggi. Hierarki kebutuhan manusia oleh Moslow ini terkenal dengan teori hierarchy of needs atau Hierarki Kebutuhan. Tingkatan kebutuhan manusia menurut Maslow adalah 1) kebutuhan fisiolofis atau dasar, 2) kebutuhan terhadap rasa aman, 3) kebutuhan untuk dicintai dan

${ }^{1}$ Sugira Wahid, Manusia Makassar (Cet. II, Makassar: Refleksi, 2008), h. 19. 
disayangi, 4) Kebutuhan dihargai, dan 5) kebutuhan aktualisiasi diri. ${ }^{2}$ Pemenuhan kebutuhan-kebutuhan manusia selaras dengan eksistensinya sebagai makhluk budaya (cultural being), sehingga dengan kemampuan akal budinya, manusia Bugis Makassar mampu memertahankan eksistensi dirinya dan budayanya sekaligus. Bahkan, Orang Bugis dan Makassar terkenal sebagai masyarakat yang masih kuat mempertahankan adat dan budayanya.

Pada dasarnya budaya memiliki nilai-nilai yang diwariskan, ditafsirkan, dan dilaksanakan seiring dengan proses perubahan sosial masyarakat. Pelaksanaannya merupakan legitimasi masyarakat terhadap budaya. ${ }^{3}$ Budaya tidak lepas dari sistem nilai yang memberi keyakinan kepada pemiliknya bahwa ada nilai yang terkandung dalam setiap ekspresi budaya. Dengan kata lain, tidak ada satu bentuk budaya yang hampa nilai.

Pengertian nilai diungkapkan dalam beberapa rumusan, tetapi dapat dikemukakan sebuah batasan, yaitu sesuatu yang dipentingkan manusia sebagai subjek, menyangkut segala sesuatu yang baik atau yang buruk sebagai abstraksi, pandangan, atau maksud dari berbagai pengalaman dengan seleksi perilaku yang ketat. ${ }^{4}$ Pengertian yang lebih sederhana adalah sesuatu yang baik dan selalu diinginkan, dicita-citakan, dan dianggap penting oleh seluruh manusia sebagai anggota masyarakat. Dikatakan memiliki nilai apabila berguna dan berharga (nilai kebenaran), indah (nilai estetika), baik (nilai moral atau etis), religius (nilai agama). ${ }^{5}$

St. Takdir Alisjahbana menyebut enam nilai yang sangat menentukan wawasan etika dan kepribadian manusia maupun masyarakat, yaitu:

1. Nilai teori, yaitu tujuan proses penilaian untuk mengetahui alam sekitar, menentukan dengan objektif identitas benda-benda dan kejadian-kejadian.

2. Nilai ekonomi, yaitu tujuan penilaian memakai benda-benda dan kejadiankejadian ke arah sebesar-besarnya kesenangan hidup.

3. Nilai agama, yaitu tujuan dalam proses penilaian dunia sekitar yang dihadapi dan sebagai ekspresi daripada rahasia dan kebesaran hidup dan alam semesta yang melahirkan rasa takzim dan ketakjuban.

4. Nilai estetika, yaitu penilaian pada keindahan dari benda-benda dan kejadiankejadian yang melahirkan keserasian.

5. Nilai kekuasaan dan solidaritas, yaitu penilaian dengan melihat sesama, merasa puas jika orang lain mengikuti norma-norma dan nilai-nilai kita. Proses penilaian solidaritas memunculkan hubungan cinta, persahabatan, simpati,

\footnotetext{
${ }^{2}$ Abraham Maslow, On Dominace, Self Esteen and Self Actualization (AnnKaplan: Maurice Basset), h. 153. Dikuti dalam http://id.m.wikipedia.org (12 November 2018)

${ }^{3}$ Rasid Yunus, "Transformasi Nilai-nilai Budaya Lokal sebagai Upaya Pembangunan Karakter Bangsa”, Jurnal Penelitian Pendidikan, Vol. 13, No. 1/2013, h. 67.

${ }^{4}$ Munandar Sulaeman, Ilmu Budaya Dasar; Sebuah Pengantar (Cet. VI; Bandung: PT Refika Aditama, 1998), h. 19.

${ }^{5}$ Elly M. Setiadi, dkk., Ilmu Sosial dan Budaya Dasar, h. 31.
} 
penghargaan, dan saling membantu.

6. Nilai ilmiah, yaitu tujuan penilaian pada kombinasi nilai teori, nilai ekonomi dan nilai solidaritas ke arah pengembangan ilmiah. ${ }^{6}$

Tiga dari nilai budaya tersebut di atas, yaitu nilai agama, seni, dan solidaritas, berkaitan dengan rasa, yang masih menurut St. Takdir Alisjahbana bersendi pada perasaan, intuisi, dan imajinasi yang jika tidak didukung oleh pemikiran yang rasional, ia mudah terjerumus ke dalam penghayatan serba mistis dan gaib yang ekstrem dan irasional. ${ }^{7}$

Sistem nilai yang sudah berwujud tradisi akan menjadi sulit berubah karena sudah menyatu dalam kehidupan masyarakat. Oleh karena itu, tampaknya tradisi sudah terbentuk sebagai norma yang dibakukan dalam kehidupan masyarakat. ${ }^{8}$

Manusia dan masyarakat manapun umumnya memperjuangkan dan membela nilai-nilai dasar yang sama. ${ }^{9}$ Karena itu, unsur norma dan sanksi dalam budaya bermaksud memertahankan unsur nilai yang ada dalam budaya. Norma merupakan standar yang ditetapkan sebagai pedoman bagi setiap aktivitas manusia, sementara sanksi adalah ganjaran atau hukuman yang memungkinkan orang mematuhi norma. ${ }^{10}$

Para ahli ilmu sosial mengobservasi bahwa para warga masyarakat menganggap semua norma yang mengatur dan menata tindakan mereka itu tidak sama. Ada norma yang sangat berat sehingga apabila terjadi pelanggaran terhadap norma seperti itu akan ada akibatnya yang panjang. Para pelanggar akan dituntut, diadili, dan dihukum. Sebaliknya, ada juga norma yang dianggap kurang berat sehingga apabila dilanggar tidak akan ada akibat yang panjang, tetapi hanya tertawaan, ejekan, atau gunjingan saja oleh masyarakat lainnya. Sosiolog W.G. Summer menyebut norma golongan pertama mores, dan norma golongan kedua folkways $^{11}$ (tata cara atau kebiasaan masyarakat).

Sistem norma dan aturan-aturan adat dalam kehidupan orang Bugis disebut ade' atau ada' dalam bahasa Makassar. Ade' adalah salah satu aspek pangadereng yang mendinamisasi kehidupan masyarakat, karena ade' meliputi

${ }^{6}$ Lihat Simuh, Islam dan Pergumulan Budaya Jawa (Cet. I; Jakarta: Teraju, 2003), h. 1-2.

${ }^{7}$ Simuh, Islam dan Pergumulan Budaya Jawa, h. 3.

${ }^{8}$ Lihat Adeng Muchtar Ghazali, Antropologi Agama; Upaya Memahami Keragaman Kepercayaan, Keyakinan, dan Agama (Cet. I; Bandung: Alfabeta, 2011), h. 33. 41.

${ }^{9}$ Rafael Raga Maran, Manusia dan Kebudayaan dalam Perspektif Ilmu Budaya Dasar, h.

${ }^{10}$ Setiap kebudayaan mempunyai tujuh unsur dasar, yaitu: kepercayaan, nilai, norma dan sanksi, simbol, teknologi, bahasa, dan kesenian. Lihat Rafael Raga Maran, Manusia dan Kebudayaan dalam Perspektif Ilmu Budaya Dasar, h. 41-42.

${ }^{11}$ Lihat Koentjaraningrat, Pengantar Ilmu Antropologi, h. 159-160. 
segala keharusan tingkah laku dalam kegiatan orang-orang Bugis. ${ }^{12}$ Hal yang sama juga berlaku bagi ada' terhadap orang-orang Makassar. Dengan demikian, ade'atau ada' merupakan unsur budaya Bugis-Makasar yang berfungsi menjaga nilai-nilai budayanya.

Di antara azas pangadereng, terdapat azas mappasilasa'e yang diwujudkan dalam manifestasi ade' agar terjadi keserasian dalam sikap dan tingkah laku manusia di dalam memperlakukan dirinya dalam pangadereng. Di dalam tindakan-tindakan operasionalnya ia menyatakan diri dalam usaha-usaha pencegahan (preventif), sebagai tindakan-tindakan penyelamat. ${ }^{13}$

Pangngadereng harus terjaga dan semua prilaku yang dianggap tidak berkesesuaian dengannya atau dapat merusaknya harus dicegah. Metode pencegahan itu diungkapkan melalui pemmali-pemmali yang disosialisasikan sejak dini dalam kehidupan rumah tangga.

Upaya pencegahan atau tindakan preventif terjadinya pelanggaran dalam perspektif dakwah disebut nahi munkar (melarang dan mencegah perbuatan tercela dan terlarang) yang menjadi bagian tidak terpisahkan dari amar ma'ruf (memerintahkan dan mendorong hal-hal yang baik).

\section{METODE PENELITIAN}

Penelitian ini merupakan deskriptif-eksploratif dengan pemaparan data secara kualitatif. Data diperoleh dari informan yang terdiri dari masyarakat Bugis dan Makassar. Pengumpulan data dilakukan dengan metode observasi dan wawancara dengan bantuan istrumen berupa pedoman wawancara. Populasi penelitian ini adalah masyarakat Bugis Makassar di Sulawesi Selatan, dan sampelnya adalah sejumlah masyarakat yang dipilih secara acak (random) pada empat kabupaten, yakni Bone, Barru, Takalar, dan Pangkep. Analisis data dilakukan dengan teknik kondensasi, display, dan penarikan kesimpulan.

\section{HASIL PENELITIAN DAN PEMBAHASAN}

Wujud dan fungsi azas mappasilasa'e dalam pangadereng, menunjukkan pemmali itu menemukan arti pentingnya, baik dalam pangadereng, maupun dalam kehidupan masyarakat Bugis dan Makassar. Meskipun menurut Mattulada, ceritacerita pemmali dalam kalangan orang Bugis digolongkan ke dalam rapang yang erat pertaliannya dengan pangadereng. Oleh karena itu pelanggaran atas pemmali menyebabkan seseorang dapat dianggap melanggar pangadereng. ${ }^{14}$

\footnotetext{
${ }^{12}$ Mattulada, Latoa; Satu Lukisan Analitis terhadap Antropologi Politik Orang Bugis, h. 339.

${ }^{13}$ Mattulada, Latoa; Satu Lukisan Analitis terhadap Antropologi Politik Orang Bugis, h. 341.

${ }^{14}$ Mattulada, Latoa; Satu Lukisan Analitis terhadap Antropologi Politik Orang Bugis, h. 61.
} 
Pemmali yang dalam bahasa Indonesia dipersepsikan dengan istilah pemali bukanlah istilah tunggal yang digunakan masyarakat tradisional untuk menamai kumpulan pantangan dan larangan adatnya, sebab pada setiap wilayah di Indonesia memiliki bahasa yang sangat beragam, tetapi makna pemali tetap diakui eksistensinya dan disebut sesuai dengan bahasa setempat. Di Sunda dan Jawa disebut dengan pamali, di Sulawesi Tenggara, khususnya di Buton disebut pomali, dan di Sulawesi-Selatan disebut pemmali (Bugis), kasipalli (Makassar) dan kapalli (Selayar).

Di Sulawesi Selatan, pemali tidak saja dikenal dan diyakini oleh dua suku yang sudah disebut di atas, tetapi juga dikenal oleh semua suku yang ada. Selain suku Bugis dan Makassar, suku besar lainnya adalah Mandar dan Toraja.

Suku Bugis dan Makassar sebagai penduduk mayoritas Sulawesi Selatan menyebut pemali secara berbeda. Dalam masyarakat Bugis, pemali dikenal dengan istilah pemmali, semantara dalam masyarakat Makassar dikenal dengan istilah kasipalli selain istilah pemmali itu sendiri. Sekalipun berbeda istilah, keduanya digunakan untuk menyatakan larangan atau pantangan terhadap seseorang dan masyarakat untuk melakukan dan atau mengatakan sesuatu yang tidak sesuai dengan keyakinan dan nilai adat dan tradisi yang diwarisi dari nenek moyang. Mereka meyakini bahwa pelanggaran terhadap pemali akan mengakibatkan ganjaran atau kutukan, dan keyakinan tersebut selalu dipegang teguh.

Sebagai suatu tradisi yang turun temurun, pemmali atau kasipalli mengandung ajaran akan nilai dan falsafah hidup yang menjadi pegangan para leluhur. Pemali dalam hal ini memegang peranan sebagai media pemeliharaan dan pelestarian nilai atau apa yang dianggap nilai.

Salah satu sumber nilai yang utama dalam kebudayaan Bugis yang kemudian dialihkan secara turun-temurun dari satu generasi ke generasi berikutnya adalah paseng atau pappangaja. Paseng bersama dengan pappangaja itu termaktub di dalam lontara'-lontara' dalam rangka pewarisan nilai-nilai dasar kebudayaan masyarakat Bugis-Makassar. Paseng berarti nasehat dan petaruh atau dengan arti wasiat yang dipertaruhkan. Ia menekankan tentang keharusan dan pantangan. ${ }^{15}$ Dengan demikian, pemmali atau kasipalli bagian dari paseng/pasang yang pantang untuk dilanggar.

Sekaitan dengan paseng atau pappasang, menurut Abu Hamid, jika seseorang atau masyarakat ternyata melanggar, maka segala hal-hal yang dianggap tabu itu, mereka mendapat teguran disertai ucapan tajangi pa'dibokoannaltajengngi pa'dimunrinna artinya tunggu akibatnya. Jika mereka telah ditimpa sesuatu yang tak diinginkan, maka masyarakat mencemoohnya

${ }^{15}$ Lihat A. Rahman Rahim, Nilai-Nilai Utama Kebudayaan Bugis, h. 66-67. 
dengan ucapan natabai pappasang/nakennai pappaseng artinya sudah ditimpa salah satu isi pesan. Sedangkan orang yang melanggar pantangan disebut pasek (orang sial). ${ }^{16}$

Selain sebagai salah satu falsafah hidup dalam kebudayaan Bugis dan Makassar, fenomena pemali yang menarik lainnya adalah nampak menyatunya dalam setiap budaya dan dikenal oleh masyarakat Indonesia, terlebih lagi kemampuannya bertahan dalam keyakinan masyarakat di tengah keyakinan terhadap agama Islam dengan berbagai aspek ajarannya. Khusus untuk kasus Sulawesi Selatan, fenomena pemali nampak tidak dapat dipisahkan dalam kehidupan masyarakat sekalipun mayoritas penduduknya sudah cukup lama menganut agama Islam, bahkan pemmali seoalah-olah sudah masuk dalam alam bawah sadar sebagian masyarakat pada semua lapisannya, mulai dari masyarakat awam sampai masyarakat intelektual.

Penerapan syariat Islam, termasuk hukum Islam banyak didakwakan dengan disertai ancaman terhadap pengabaiannya. Islam dan aturan-aturan syariat Islam disampaikan melalui dakwah dalam berbagai bentuknya. Dakwah sendiri memiliki padanan dengan istilah-istilah yang lain yaitu: tablìg, khutbah, nași ḥaḥ,

tabsyīr wa tanzīr, wașiyyah, amr al-ma'rüf wa nahy 'an al-munkar, tarbiyyah wa ta limm. $^{17}$ Di antara padanan dakwah di atas, kata tanzir yang berarti memberi ancaman atau perhatian nampaknya relevan dengan ancaman pelanggaran terhadap pemali.

Tanzīr dalam kegiatan dakwah yaitu menyampaikan uraian keagamaan kepada orang lain yang isinya peringatan atau ancaman bagi orang-orang yang melanggar syariat Allah swt. Tanzīr diberikan dengan harapan orang yang menerimanya tidak melakukan atau menghentikan perbuatan dosa. ${ }^{18}$ Tanzir selalu menginformasikan kepada manusia untuk tidak bermain-main dengan aksi kejahatan atau tindakan melawan perintah agama (Islam), karena setiap kesalahan atau perlawanan hukum syara' akan mendapat ancaman azab sesuai dengan tingkat kesalahan yang dilakukannya. Karena itulah, al-Qur'an menginformasikan bahwa Allah swt. telah menyiapkan neraka sebagai sejelek-jelek tempat kembali bagi siapapun yang melakukan pembangkangan terhadap seruan dan syariat Islam. ${ }^{19}$ Demikian dampak pelanggaran pemali yang lebih merupakan ancaman

\footnotetext{
${ }^{16}$ Abu Hamid, Pesan-Pesan Moral Pelaut Bugis (Cet. I; Makassar: Pustaka Refleksi, 2007), h. 74.

${ }^{17}$ Moh. Ali Aziz, Ilmu Dakwah, Edisi Revisi (Cet. II; Jakarta: Prenada Media Group, 2004), h. 20.

${ }^{18}$ Salma, "Metode dan Pengaplikasian Dakwah Islam Di Lembaga Studi Islam Assalaam Manado (Siam) Provinsi Sulawesi Utara”. Jurnal Aqlam; Journal of Islam and Plurality, Volume 2, Nomor 2, Desember 2017, h. 82

${ }^{19}$ Juhari, "Perubahan Sosial dalam Perspektif Dakwah" Jurnal Al-Bayan. VOL. 21, NO. 32, JULI-DESEMBER 2015
} 
dengan tujuan untuk menguatkan pemali dan sekaligus mencegah terjadinya dampak buruk akibat tidak mengindahkan pantangan.

Istilah-istilah dakwah seperti yang disebutkan di atas, tidak dapat dipisahkan dengan kegiatan dakwah, karena kesemua istilah tersebut merupakan sarana untuk menyampaikan dakwah yang dimaksud. Hanya istilah yang dipakai saja yang berbeda, namun inti daripada semua istilah tersebut adalah menyeru kepada kebaikan dan mencegah kemungkaran dengan menggunakan metode tertentu sesuai dengan ketentuan yang telah digariskan oleh Allah swt. dan RasulNya. ${ }^{20}$

Terdapat sejumlah ayat al-Qur'an yang menyebut tabsyīr dan tanzīr. Di antaranya adalah QS al-Isra'/17: 105 dan QS al-Baqarah/2: 119. Tabsyīr dan tanzīr selalu disebut beriringan dalam bentuk kata sifat (ism fa'il), yakni basyīr dan nazīr. Jika keduanya disebut, kata basyīr selalu didahulukan dari kata nazīr. Ini dapat diartikan bahwa tabsȳr atau menyampaikan kabar gembira harus diutamakan dari tanzīr atau ancaman atas dosa dan perbuatan jahat. ${ }^{21}$

Pemali dalam masyarakat Bugis dan Makassar tidak berdiri sendiri, tetapi beriringan dengan pappangaja (dakwah/ajakan) dan paseng (nasehat). Pemali digunakan sebagai bagian dari upaya menguatkan terpenuhinya pappangaja dan terlaksananya paseng. Sebagai mana disebutkan sebelumnya, paseng berarti nasehat dan petaruh atau dengan arti wasiat yang dipertaruhkan dan menekankan tentang keharusan dan pantangan.

Di antara bentuk pemali yang memuat ajaran moralitas adalah:

1) Bangun terlambat atau bermalas-malasan, karena dipercayai rejekinya pada hari itu hilang

2) Bekerja pada tengah hari, nanti kena parang atau cangkul.

3) Bepergian saat ada orang yang sedang makan, karena bisa terjadi bahaya saat bepergian

4) Berbicara dan bernyanyi saat memasak di dapur bagi gadis, nanti akan mendapat jodoh yang tua umurnya

5) Berdiri di depan pintu, ditakutkan terkena ilmu hitam (guna-guna)

6) Berlama-lama mandi bagi anak muda, suatu saat nanti mendapat pasangan yang tua (berumur)

7) Bernyanyi di dalam kamar mandi, karena sulit dapat jodoh, dan suatu saat akan meneteskan air mata

8) Berpindah-pindah saat makan, akibatnya akan memiliki banyak suami

9) Berpura-pura menangis, akan berakibat orang tua akan menerima musibah

\footnotetext{
${ }^{20}$ Salma, "Metode dan Pengaplikasian Dakwah Islam Di Lembaga Studi Islam Assalaam Manado (Siam) Provinsi Sulawesi Utara", h. 86.

${ }^{21}$ Salma, "Metode dan Pengaplikasian Dakwah Islam Di Lembaga Studi Islam Assalaam Manado (Siam) Provinsi Sulawesi Utara”, h. 82.
} 
10) Bersedih pada saat hamil, karena kelak akan mendapatkan anak cengeng

11) Bersendawa di depan orang banyak, agar tidak dinilai kurang sopan oleh orang lain

12) Buang air kecil di bawah pohon yang dianggap keramat, karena membuat penunggu pohon tersingggung dan marah, bahaya.

13) Duduk dengan memeluk bantal, orang pemalas/malas bekerja dan suka berpangku tangan

14) Duduk di atas batu nisan kuburan, karena dapat mengakibatkan sakit perut

15) Duduk di depan pintu, karena akan menghalangi rezeki

16) Duduk di depan pintu, nanti ia tidak menikah (tidak dapat jodoh)

17) Duduk di depan pitu pada waktu malam, akan kemasukan setan

18) Duduk di jalan atau pintu bagi orang hamil, karena mengakibatkan ana yang ada di dalam perut teringgal di pintu (sulit) saat melahirkan

19) Duduk di lesung, karena dapat mengakibatkan akan di mangsa oleh buaya

20) Duduk di patungkulu, karena menunggu kesusahan (akan ditimpa masalah).

21) Keluar rumah menjelang magrib, karena akan dpengaruhi oleh setan

22) Makan berpindah-pindah tempat, karena akan sering menikah (kawin cerai)

23) Makan bersuara, nanti ompong

24) Makan dan minum menggunakan penutup, karena akan dijadikan penutup malu orang lain

25) Makan daun kelor saat hamil, karena mengakibatkan banyaknya lendir yang menyerupai getah

26) Makan dengan air sayur/air ikannya terlalu banyak, suatu saat nanti pada saat menikah maka akan datang hujan deras/banjir ()

27) Makan dengan beralaskan tutup panci, karena akan dijadikan sebagai orang penutup malu

28) Makan dengan menggunakan piring kecil, karena rezekinya juga sedikit

29) Makan menggunakan penutup alat makan bagi remaja laki-laki, karena akan dijadikan penutup malu (passampo siri), menikahi perempuan hamil yang bukan perbutannya.

30) Makan menggunakan penutup panci, karena sulit bertemu jodoh

31) Makan sambil bersin, tidak sopan.

32) Makan sambil cerita, karena tidak menikmati makanan

33) Makan sambil tidur (baring) bagi orang yang hamil, nanti katika melahirkan akan buang air besar

34) Makan/minum degan memakai tangan kiri, karena setan ikut makan

35) Melanggar pangadakkang (aturan adat), seperti kappara (Loyang besar) harus di atas, di bawah, jika dilanggar akan dirasuki leluhur

36) Melangkahi orang tidur/baring, nanti orang tua (ibu)nya meninggal 
37) Meludah saat buang air, nanti bisa timbul jerawat (jerawatan)

38) Memakai da'dasa (sigara) bagi penganting perempuan

39) Memakai pakaian yang masih basah, karena dapat meninggal dunia

40) Memakan kelapa terlalu banyak, karena dapat mengakibatkan gatal pada dubur

41) Membaca buku dalam keadaan baring, karena akan membuat mata cepat rabun

42) Membiarkan pintu rumah terbuka (harus menutup pintu dan jendela ketika menjelang waktu magrib), karena dipercaya setan bisa masuk rumah

43) Membuang air panas (secara) langsung ke tanah, karena dipercaya bahwa tanah termasuk makhluk hidup

44) Membuang bantal ke tanah, karena orang bisa sakit kepala, atau meninggal dunia

45) Membuka payung di dalam rumah, akan terjadi sesuatu yang buruk dalam keluarga

46) Memeluk kedua kaki (duduk sambil memeluk kaki atau lutut), mendatangkan kesialan

47) Memotong kuku pada malam hari, akan mengakibatkan kecelakaan (mate' maddara)

48) Memotong/memangkas rambut saat malam,

49) Memukul dengan sapu lidih, nanti tidak menikah

50) Menaikkan kaki di dinding pada saat baring, karena akan sering difitnah

51) Menaikkan tangan ketika tidur karena akan menyerah sebelum bertempur

52) Menaruh tangan di tas kepala, nanti punya istri yang tidak baik

53) Mencari kutu di waktu malam, kurang rezeki

54) Mencukur alis sebelum menikah, karena wajah tidak akan berseri saat di pelaminan

55) Mencukur rambut di malam hari, karena dipercaya akan mendatangkan kesialan

56) Menduduki bantal (tudangi angkalulung), nanti akan terkena bisul

57) Mengalungkan sarung di leher, nanti mati berdarah

58) Mengejek atau mencela seseorang bagi Ibu hamil, karena dipercaya kelak anaknya yang akan lahir seperti orang yang diejek atau dicela

59) Membunuh hewan atau menyakiti atau mencela sesuatu ketika istri sedang hamil, karena anaknya akan sama dengan yang dicela

60) Menggigit bibir bagian bawah, kelak akan bernasib buruk dan rezeki akan surut

61) Menghabiskan nasi di panci, dikarenakan di waktu malam malaikat yang menjaga rumah ingin makan

62) Menghayal di waktu magrib, ditakutkan kemasukan setan (kesurupan) 
63) Mengijak kaki orang lain, nanti ibunya akan meninggal

64) Mengintip, karena dapat mengakibatkan sakit mata

65) Meninggalkan cucian piring (tidak dicuci) sebelum bepergian, karena dapat mengakibatkan kejadian-kejadian yang tidak diinginkan di tengah perjalanan

66) Meninggalkan makanan/minuman yang sudah dihidangkan tanpa mencicipi, karena merupakan penolakan terhadap rejeki, sedangkan menikmati hidangan merupakan bentuk penghormatan tamu terhadap tuan rumah.

67) Menjahit malam, ditakutkan tertusuk jarum

68) Menjahit saat sedang hamil, karena menyebabkan tidak sempurna kondisinya

69) Menjatuhkan kelapa di tangga, karena dapat memendekkan usia, (atau) mendatangkan balak pada rumah tersebut

70) Menjatuhkan timba dari atas rumah, karena biasanya rumah dan penghuninya ditimpa bala (musibah)

71) Menyapu di malam hari, dikarenakan menyapu rezeki

72) Menyela khatib ketika di mimbar, bisa mengalami musibah

73) Menyentuh anak ketika selesai bersetubuh nanti anaknya demam

74) Menyisakan makanan yang sedang dimakan, karena mengakibatkan rejeki beras menurun

75) Meratap atau memukul diri saat melayat, karena mayat/mayit semakin jauh dari kebaikan

76) Makan nasi dari baki besar (kappara) bagi orang hamil, nanti meninggal saat berlayar (mate mallureng atau tenggelam)

77) Melangkahi kayu bakar (attapang) bagi orang hamil, nanti anak melintang (ta'bampang) dalam perut ibunya

78) Membiarkan rambutnya terurai (mapparampa') bagi orang hamil, nanti setan menggantung di rambutnya

79) Membuang sesuatu lewat jendela bagi rang hamil, dikarenakan pada saat melahirkan tidak melalui jalan operasi

80) Membunuh binatang orang hamil, nanti ia tidak selamat

81) Orang hamil menjadikan sarung lipat (leppe' lipa') alas kepala (makka'nggulung), nanti anakny aterlipat dalam perut

82) Orang hamil singgah di tangga saat mau turun ke tanah, nanti sulit melahirkan

83) Orang hamil tidur siang, nanti keenakan (kanyamengeng) menjelang ia melahirkan

84) Orang hamil tinggal atau berdiri di pintu sebab anaknya akan meninggal dalam perut 
85) Mengurai rambut bagi perempuan ketika bepergian, karena dapat menyebabkan setan bergelantungan pada rambutnya

86) Pergi (Bepergian) tanpa sepengetahuan oran tua, akan terjadi musibah/sakit-sakitan

87) Potong kuku di dalam rumah, karena cepat atau lambat ada di antara keluarga yang meninggal dan hanya air jenazah yang dapat membersihakan kuku tersebut

88) Potong kuku di malam hari, karena akan membuat umur orang tersebut menjadi pendek

89) Tengkurap (makkandoppang), karena orang tuanya (ibu) atau keluarga dekat yang cepat meninggal.

90) Terlambat kembali ke rumah kalau pergi (harus datang sebelum magrib)

91) Tidur dengan kaki mengarah ka'bah (kiblat), bassung (pelecehan)

92) Tidur dengan lampu menyala, karena cahaya lampu itu akan diserap oleh mata dan berdampak negatif dalam kehidupan

93) Tidur di waktu pagi, kurang rezeki

94) Tidur menghadap utara (manorang) seperti posisi jenazah, karena akan cepat mati

95) Tidur menjelang magrib, karena bisa dirasuki setan

96) Tidur pada hari jumat, karena biasanya mudah ditimpa bala (musibah) berupa penyakit.

97) Tidur pada saat jumat, nanti dimasuki setan (kesurupan)

98) Tidur pada saat khutbah jumat, bisa mendatangkan penyakit

99) Tidur pada saat magrib, karena mudah masuk pengaruh jahat, biasanya kesurupan

100)Tidur sore dan makan sore, karena sial, tanaman palawija tidak berhasil (gagal panen)

Pemali-pemali di atas merupakan bentuk dan upaya pelarangan dan pencegahan (nahi) terhadap segala hal yang dianggap terlarang atau tercela (munkar). Pada saat yang sama mengandung nilai edukatif dan moralitas dalam rangka pembentukan karakter di samping membangun etos kerja. Hal itu bermanfaat dalam menguatkan pangadereng, juga berperan dalam pengelolaan ekonomi keluarga dan masyarakat. Pemali-pemali dimaksudkan untuk menanamkan kedisiplinan, kamandirian, dan bekal etika atau moralitas. ${ }^{22}$ Semua nilai baik itu sesungguhnya merupakan hal-hal ma'ruf (kebajikan) yang menjadi fungsi dakwah Islam.

Ajaran Islam menghendaki keteraturan hidup dalam bimbingan dan

${ }^{22}$ Wahyuni, Sosiologi Bugis Makassar, h. 84. 
petunjuk syariat demi terciptanya kehidupan manusia yang bahagia. Tujuan utama syariat Islam adalah tercapainya lima manfaat mendasar bagi umat manusia, terutama umat Islam, yaitu: terlindunginya jiwa, terjaganya akal, terpeliharanya agama, terpeliharanya keturunan, dan terjaganya harta benda. Berdasarkan lima tujuan mendasar tersebut, maka manusia mesti mengupayakan segala sesuata yang dapat mendukungnya dan menghindari semua hal yang dapat menghalanginya.

Salah satu di antara dua belas butir adab ilmuan terhadap dirinya agar patut dicontoh dan dijadikan teladan adalah menyebarkan salam amar ma'ruf dan nahi mungkar. ${ }^{23}$ Bahkan tugas ini adalah tanggung jawab bersama, laki-laki dan perempuan. Salah satu tugas dan peranan utama perempuan dalam masyarakat berdasarkan petunjuk al-Qur'an adalah kerjasama dalam melaksankan amar ma'ruf nahi mungkar, baik terhadap keluarga terdekat maupun lainnya, sehingga silaturrahim (arhām) tetap terpelihara dengan penuh kasih sayang, kedamaian, dan kebahagiaan. $^{24}$

Masyarakat Bugis dan Makassar idealnya mampu mewujudkan tujuan pokok hukum Islam dengan memaksimalkan potensi paseng dalam mengajak, menanamkan, dan mendidik anak-anak megenai moralitas dan etos kerja (konstruktif), dan menjalankan peran pemali dalam hal pencegahan segala hal yang dekonstruktif.

Pemali-pemali yang dikategorikan dalam ajaran moralitas Bugis Makassar bertujuan sama dengan ajaran Islam yang menghendaki terealisasinya akhlak yang mulia dalam masyarakat. Sebagian dari pemali-pemali moralitas tersebut ada yang juga memang merupakan bagian dari nasihat Rasulullah saw seperti dapat dilihat dalam hadis berikut:

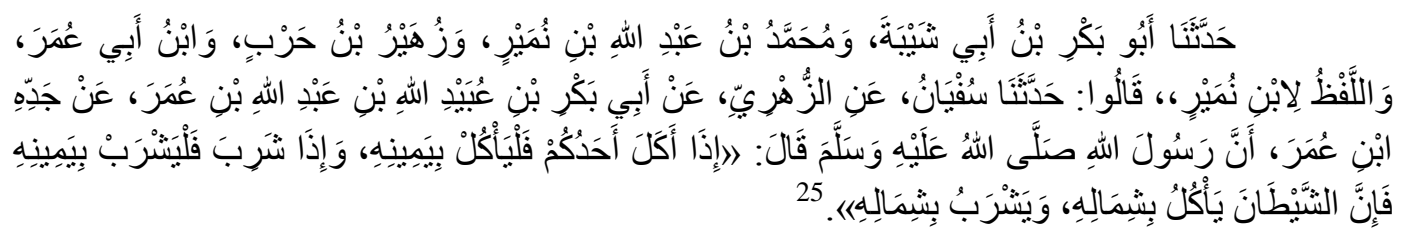

Artinya:

Abu Bakr ibn Abi Syaibah, dan Muhammad ibn 'Abdullah ibn Nmair, dan Zuhair ibn Harb, dan Ibn Abi 'Umar, dan lafaz dari Ibn Numair, mereka berkata, Telah menceritakan kepada kami Sufyan, dari al-Zuhriyy, dari Abi Bakr ibn 'Ubaidillah ibn Abdillah ibn 'Umar, dari kakeknya Ibn 'Umar, bahwa Rasulullah saw bersabdah: "Apabila seseorang di antara kalian makan hendaknya ia makan dengan tangan kanan dan jika ia minum

\footnotetext{
${ }^{23}$ Lihat Gustia Tahir, "Sinergitas Ilmu dan Adab", Jurnal Adabiyah XV, nomor 1 (2015), h. 22-23.

${ }^{24}$ Lihat Marwati, "Pemberdayaan Perempuan (Kajian Tafsir al-Qur'an Surah al-Nisa Ayat 1)", Jurnal Adabiyah 15, nomor 2 (2015), h. 108.

${ }^{25}$ Muslim ibn al-H\{ajjaj al-Naisaburi, Sahih Muslim, juz 3, Bab Adab al-Ta'am wa alSyarab wa Ahkamihima, hadis no. 2020, h. 1598.
} 
hendaknya minum dengan tangan kanan, karena sesungguhnya setan itu makan dengan tangan kirinya dan minum dengan tangan kirinya." (HR Muslim).

Nasihat Nabi saw untuk makan dan minum dengan tangan kanan dan tidak dengan tangan kiri dipantangkan oleh dalam masyarakat dengan ungkapan pemali. Dengan demikian, pemali ini berkesesuaian dengan sunah Rasulullah saw.

Bentuk-bentuk pemali yang dikenal masyarakat Bugis dan Makassar banyak yang menyangkut nilai moralitas atau pendidikan (proses pengubahan sikap dan tata laku dalamupaya mendewasakan manusia melalui upaya penjaran dan pelatihan). Hal ini sejalan dengan konsep pangadereng yang menginginkan terwujudnya keteraturan dan ketertiban hidup dalam masyarakat Bugis dan Makassar.

Pemali sebagai salah satu bentuk kekayaan budaya masyarakat Bugis dan Makassar, bertujuan sebagai pegangan moral yang mampu membentuk pribadi luhur dan berperan sebagai pendidikan budi pekerti. ${ }^{26}$

St. Kuraedah dkk. menyimpulkan bahwa pemmali yang diterapkan secara turun temurun adalah metode pendidikan yang efektif di Indonesia yang mengajarkan nilai pendidikan karakter. Banyak nilai karakter pendidikan yang dapat dipelajari dalam budaya pemmali pada masyarakat Bugis Makassar, seperti nilai disiplin dalam bekerja dan beribadah, pengelolaan pekerjaan yang terencana, pendidikan pranikah yang dapat dilakukan dengan menanamkan manajemen kerja lebih dini sehingga seorang wanita, misalnya, dapat membangun kehidupan yang harmonis dengan suaminya. Selain itu, keluarga juga dapat memutuskan untuk fokus pada pekerjaan, pendidikan kebersihan, kesehatan, ketertiban, dan keteraturan, tidak boros, pembelajaran agama, sosial, pendidikan kesadaran gender tentang kesetaraan/persamaan hak dan kewajiban setiap orang manusia dengan doktrin etika dalam bisnis. Namun demikian, tidak bisa disangkal bahwa ada juga sejenis pemmali yang perlu diluruskan, tidak mengandung mitos yang bermakna seperti menganggap benda mati sebagai makhluk hidup yang dapat memberikan perlindungan, karena hal itu dapat mengarah kepada kesyirikan. ${ }^{27}$

Moralitas bagi masyarakat Bugis dan Makassar dianggap penting bahkan menjadi bagian dari falsafah hidup yang tersampul dalam pangadereng. Upaya yang ditempuh dalam mengajarkan moralitas dan membuatnya terpatri dalam pola kehidupan sosial adalah dengan menyampaikan pappangaja (pesan-pesan) moral, baik secara langsung dengan mesehati anak atau tidak langsung dengan memberi

\footnotetext{
${ }^{26}$ Juma Darmapoetra, Suku Bugis, Pewaris Keberanian Leluhur (Cet. I; Makassar: Arus Timur, 2014), h. 70.

${ }^{27}$ St. Kuraedah, Marlina Ghazali1, dan Pairin, "Analysis of Character Education Values in Pemmali Culture of Bugis Makassar Society", h. 5.
} 
contoh seperti mappatabe dan bersalaman (jabat tangan). Bentuk pendidikan yang lain dengan memberi semacam filter terhadap apa yang boleh dan yang tidak boleh dikatakan dan dilakukan. Filter yang dimaksud adalah pemali.

Pemali dalam keadaan ini, di samping merupakan objek pendikan atau ajaran moralitas, juga berperan sebagai bentuk atau metode pendidikan, paling tidak, ia menjadi bagian dari metode yang menguatkan penerimaan pesan dengan adanya ancaman bagi yang mengabaikan. Ancaman yang menyertai pesan dan larangan nampaknya memiliki pengaruh bagi terealisasinya pesan dan dihindarinya larangan.

Bentuk-bentuk pemali yang diungkapkan masyarakat Bugis dan Makassar di Sulawesi Selatan kaya dengan muatan nilai solidaritas sosial. Nilai yang memunculkan hubungan cinta, persahabatan, simpati, penghargaan, dan saling membantu antar sesama.

Nilai solidaritas sosial nampak dalam bentuk-bentuk pemali yang diikuti dengan bahaya (ancaman) bagi yang tidak mengindahkannya. Tanpa mengabaikan kemungkinan terjdinya ancaman yang mengikutinya, dapat ditemukan alasan lain yang terdapat dibalik pemali tersebut.

a. Pemali bepergian (berangkat) sementara dihidangkan makanan, atau meninggalkan makanan/minuman yang sudah dihidangkan tanpa mencicipi. Pemali ini terkait dengan banyak nilai solidaritas yang tak luput dari tuntunan ajaran Islam.

Menghidangkan jamuan bagi masyarakat Bugis dan Makassar sudah menjadi tradisi yang melekat erat sebagai bentuk solidaritas. Tradisi ini sejalan dengan hukum Islam tentang menghormati tamu. Nabi saw. bersabda:

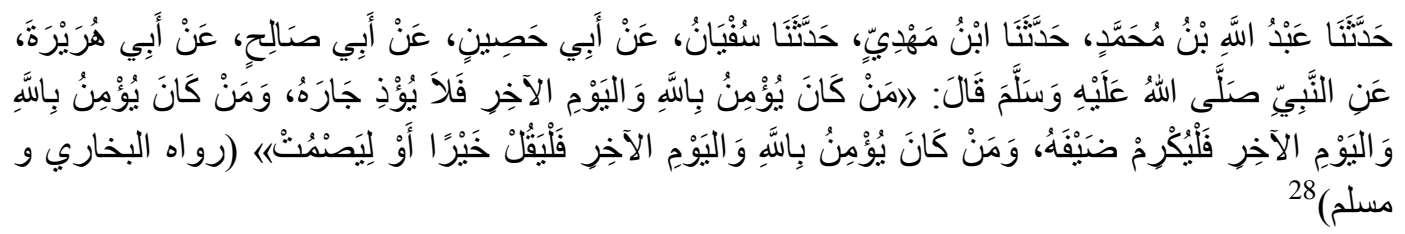

Artinya:

Telah menceritakan kepada kami 'Abdullāh bin Muhammad, telah menceritakan kepada kami Ibnu Mahdi, telah menceritakan kepada kami Sufyān dari Abī Hasīn dari Ab̄̄ Sālih dari Abī Hurairah dari Nabi saw. Bersabda: "Barangsiapa yang beriman kepada Allah swt. dan hari akhir, maka jangan menyakiti tetangganya. Barangsiapa yang beriman kepada Allah swt. dan hari akhir, maka hendaklah memuliakan tamunya. Dan barangsiapa beriman kepada Allah swt. dan hari akhir, hendaklah berkata baik atau diam”. (HR. Bukhari dan Muslim)

\footnotetext{
${ }^{28}$ Muhammad bin Isma'il Abu 'Abdillah al-Bukhari, Sahih al-Bukhari, juz 8, Bab Ikram al-Daif wa Khidmatuh Iyyah Binafsih, hadis no. 6136, h. 32. Lihat juga Muslim ibn al-Hajjaj alNaisaburi, Sahih Muslim, juz 1, Bab al-Has 'ala Ikram al-Jar wa al-Daif, hadis no. 47, h. 68.
} 
Hadis tersebut menjadi dasar hukum wajibnya menghormati tamu. Adapun salah satu bentuk yang paling kongkrit bagi masyarakat Buis dan Makassar dalam memuliakan tamu adalah dengan memberikan jamuan.

Mencicipi jamuan adalah harapan dan kebahagian bagi yang menghidangkan. Bepergian dengan meninggalkan jamuan adalah sikap yang kurang dapat diterima, bahkan dapat menyisakan goresan kekecewaan. Meninggalkan orang yang hatinya kecewa bahkan terluka tentu kurang baik dibawa serta dalam perjalanan, doa keselamatan yang diharapkan selama perjalanan boleh saja tidak didapatkan, bahkan tidak menutup kemungkinan terucap sesuatu yang negatif dari lisannya, sehingga dengan itu sesuatu yang tidak diharapkan terjadi dalam perjalanan. Dampak minimal dengan meninggalkan jamuan adalah kurangnya rasa simpati dan rasa saling menghargai dalam kalangan masyarakat.

Setiap orang tentu mengharapkan doa dan harapan yang baik, maka sudah sepantasnya setiap orang menghindari segala sesuatu yang dapat menutupi harapan baik dari orang lain, salah satunya dengan sikap yang sederhana, yakni mencicipi makanan meski sedikit saja sebagai bentuk penghargaan kepada orang yang memberi jamuan.

Di balik harapan orang yang memberi jamuan agar dicicipi hidangannya, tersirat keinginan agar orang yang akan bepergian merasa senang dengan mendoakan keluarga atau orang yang ditinggal. Di antara tuntunan Islam ialah tamu hendaknya mendoakan orang yang memberi hidangan kepadanya setelah selesai mencicipi makanan. Di antara doa yang diajarkan:

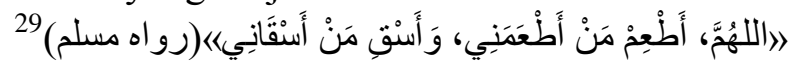

Artinya:

Ya Allah berikanlah makanan kepada orang telah yang memberikan makanan kepadaku dan berikanlah minuman kepada orang yang telah memberiku minuman. (HR. Muslim)

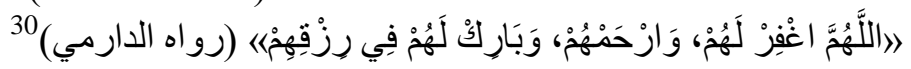

Artinya:

Ya Allah ampuni dosa mereka, kasihilah mereka, dan berkahilah rezeki mereka. (HR. Al-Dārimī)

b. Pemali menghabiskan nasi di panci, dikarenakan di waktu malam malaikat yang menjaga rumah ingin makan. Pemali ini masih terkait dengan pemali sebelumnya. Menurut Farid Wajedi, orang tua memjadikan pantangan kosongnya tempat beras

\footnotetext{
${ }^{29}$ Muslim ibn al-H\{ajjaj al-Naisaburi, Sahih Muslim, juz 3, Bab Ikram al-Daif wa Fadl Isarih, hadis no. 2055, h. 1625.

${ }^{30} \mathrm{Abu}$ Muhammad 'Abdullah bin 'Abdirrahman bin al-Fadl bin Bahram bin 'Abd alSamad al-Darimi, Sunan al-Darimi, juz 2 (Cet. I; al-Mamlakah al'Arabiyyah al'Su'udiyyah: Dar al-Mugni, 2000), Bab al-Du'a li Sahib al-Ta 'am iza At'am, hadis no. 2065, h. 1286.
} 
di malam hari untuk tujuan antisipatif, kalau-kalau ada tamu yang datang di malam hari. Kesiapan nasi di panci atau beras di tempat penyimpanan tentu memudahkan bagi tuan rumah untuk menjamu tamu. ${ }^{31}$

Dalam hukum Islam, haram hukumnya membiarkan tamu kelaparan hingga malam hari, berdasarkan hadis:

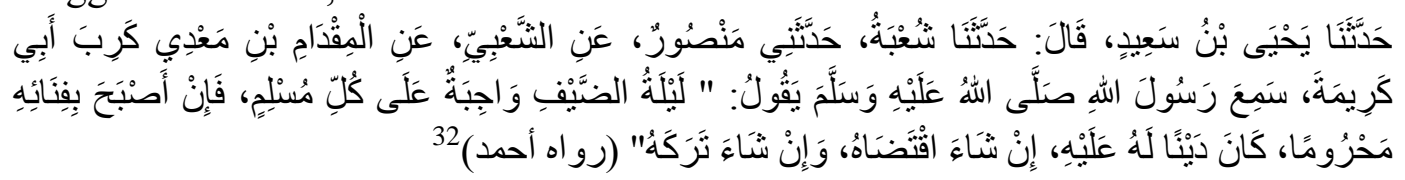

Artinya:

Imam Ahmad mengatakan, telah menceritakan kepada kami Yahya bin Sa‘īd, telah menceritakan kepada kami Syu'bah, telah menceritakan kepadaku Mansūr, dari al-Sya 'bī, dari al-Miqdām bin Ma'dī Karib Abī Karīmah yang mendengar bahwa Rasulullah saw. bersabda: "Jamuan malam bagi tamu adalah wajib atas setiap orang muslim, dan jika si tamu dalam keadaan lapar di halaman rumahnya pada pagi harinya, maka hal itu merupakan utang bagi pemilik rumah. Jika si tamu menginginkan jamuan, ia boleh menagihnya, dan boleh pula meninggalkannya. (HR. Ahmad)

c. Pemali bepergian bagi calon pengantin, karena rawan terkena musibah.

Pemali ini merupakan bentuk perhatian dalam menjaga calon pengantin agar tetap selamat dan sehat hingga berlangsungnya akad nikah atau pesta perkawinan. Banyak hal yang memungkinkan batalnya pernikahan yang dapat menyebabkan rusaknya persaudaraan, kekeluargaan, dan kekerabatan. Batalnya pernikahan tentu merupakan musibah, bukan saja bagi calon pengantin tapi juga bagi keluarga besar kedua calon pengantin.

d. Pemali bepergian (keluar rumah) lewat pintu belakang (harus pintu depan), pekerjaan/tujuan yang ingin dicapai gagal. Pemali ini merupakan bentuk kewaspadaan akan kecurigaan tetangga atau orang lain, sebab pintu belakang merupakan pintu yang tak lazim dilewati.

Solidaritas sosial dalm Islam memiliki dua manifestasi; positif dan negative. Manifestasi positif adalah saling tolong-menolong yang konstruktif, kasih sayang, saling mencintai dan menyayangi, memenuhi hak, menjalin komunikasi antar sesama, dan lain-lain sebagainya. Adapun manifestasi negatif adalah menghentikan kezaliman, tidak menuruti nafsu dan hasutan musuh, tidak dusta, tidak memfitnah, dan meninggalkan atau tidak melakukan hal-hal yang negatif lainnya. ${ }^{33}$

\footnotetext{
${ }^{31}$ Farid Wajedi (75 tahun), pimpinan Pondok Pesantren DDI Mangkoso, Wawancara, Barru, 10 April 2018.

${ }^{32} \mathrm{Abu}$ 'Abdillah Ahmad bin Muhammad bin Hanbal, Musnad al-Imam Ahmad bin Hanbal, juz 28, Bab Hadis al-Miqdam Ma'di Karib al-Kindi, hadis no. 17172, h. 409.

${ }^{33}$ Lihat Wahbah Az-Zuhaili, Akhlaq al-Musli; 'Alaqatuhu bi al-Mujtama'i. Terj. Abdul Aziz, Ensiklopedi Akhlak Muslim, Berakhlak dalam Bermasyarakat (Cat. I; Jakarta: Noura Books, 2014), h. 37.
} 
Pemali, di samping melarang perkataan dan perbuatan-perbuatan yang dianggap negatif dan berdampak buruk, juga berinflikasi pada keharusan mengerjakan lawan dari yang dipantangkan. Pemali seperti ini menyebabkan sebuah keharusan dan tidak diungkapkan dengan ungkapan pemali, tetapi yang diwujudkan dalam perbuatan.

\section{PENUTUP/SIMPULAN}

Masyarakat Bugis dan Makassar senantiasa menjaga nilai yang paling fundamental yng sudah disepakati, yakni siri'. Nilai inilah yang menjadi inti dari pangadereng. Pelaksanaannya senantiasa dijaga dan dikontrol melalui du acara, yaitu: 1. paseng (peringatan) atau tazkirah atau menyampaikan pesan (wasiyah), 2. Pemmali atau pelarangan dan pencegahan. Paseng untuk mengarahkan pada nilai-nilai baik pangngadereng, dan pemmali sebagai upaya preventif untuk tidak melakukan segala hal yang bertentangan dengan pangadereng. Paseng dalam ilmu dakwah bertujuan untuk amar ma'ruf sementara pemmali bermuara pada nahi mungkar. Amar ma'ruf dan nahi mungkar dalam ilmu dakwah merupakan bagian dari fungsi kegiatan dakwah yang hendak diwujudkan dengan beragam metode, di antaranya adalah dengan metode tabsyīr dan tanzīr. Metode tanzīr yang berarti peringatan dengan ancaman ini ditempuh oleh leluhur masyarakat Bugis Makassar dengan pemmali.

\section{DAFTAR PUSTAKA}

Al-Bukhārī, Muhammad bin Isma' ‘̄l Abū 'Abdillāh. Sahih al-Bukhārī, juz 4. Cet. I; t.t.: Dār Tūq al-Najāt, 1422 H.

Al-Naisābūrī, Muslim ibn al-Hajjāj. Sahih Muslim, juz 1. Beirut: Dār Ihyā' alTurās $\backslash$ al-'Arabī, t.th. Bab Bayān al-Kabā'ir wa Akbaruha, hadis no. 89.

Aziz, Moh. Ali. Ilmu Dakwah, Edisi Revisi. Cet. II; Jakarta: Prenada Media Group, 2004.

Az-Zuhailī, Wahbah. Akhlaq al-Musli; 'Alāqatuhu bi al-Mujtama 'i. Terj. Abdul Aziz, Ensiklopedi Akhlak Muslim, Berakhlak dalam Bermasyarakat. Cat. I; Jakarta: Noura Books, 2014.

Darmapoetra, Juma. Suku Bugis, Pewaris Keberanian Leluhur. Cet. I; Makassar: Arus Timur, 2014.

Farid Wajedi (75 tahun), pimpinan Pondok Pesantren DDI Mangkoso, Wawancara, Barru, 10 April 2018.

Ghazali, Adeng Muchtar. Antropologi Agama; Upaya Memahami Keragaman Kepercayaan, Keyakinan, dan Agama. Cet. I; Bandung: Alfabeta, 2011.

Hamid, Abu. Pesan-Pesan Moral Pelaut Bugis. Cet. I; Makassar: Pustaka Refleksi, 2007. 
Ibn Hanbal, Abū 'Abdillah Ahmad bin Muhammad. Musnad al-Imām Ahmad bin Hanbal, juz 6. Cet. I; t.t.: Muassasah al-Risālah, 2001), Bab Musnad 'Abdillah bin Mas'ūd r.a., hadis no. 3600.

Juhari, "Perubahan Sosial dalam Perspektif Dakwah" Jurnal Al-Bayan. VOL. 21, NO. 32, JULI-DESEMBER 2015.

Koentjaraningrat, Pengantar Ilmu Antropologi. Cet. IX; Jakarta: Rineka Cipta, 2009.

Maran, Rafael Raga. Manusia dan Kebudayaan dalam Perspektif Ilmu Budaya Dasar. Cet. III; Jakarta: Rineka Cipta, 2007.

Marwati, "Pemberdayaan Perempuan (Kajian Tafsir al-Qur'an Surah al-Nisa Ayat 1)", Jurnal Adabiyah 15, nomor 2 (2015), h. 108.

Maslow, Abraham. On Dominace, Self Esteen and Self Actualization (AnnKaplan: Maurice Basset), h. 153. Dikuti dalam http://id.m.wikipedia.org (12 November 2018)

Mattulada. Latoa; Satu Lukisan Analitis terhadap Antropologi Politik Orang Bugis. Yogyakarta: Gadjah Mada University Press, 1985.

Muslim ibn al-Hajjaj al-Naisaburi, Sahih Muslim, juz 3, Bab Adab al-Ta'am wa al-Syarab wa Ahkamihima, hadis no. 2020, h. 1598.

Rahim, A. Rahman. Nilai-Nilai Utama Kebudayaan Bugis. Cet. II; Yogyakarta: Ombak, 2011.

Salma, "Metode dan Pengaplikasian Dakwah Islam Di Lembaga Studi Islam Assalaam Manado (Siam) Provinsi Sulawesi Utara". Jurnal Aqlam; Journal of Islam and Plurality, Volume 2, Nomor 2, Desember 2017, h. 82.

Salma, "Metode dan Pengaplikasian Dakwah Islam Di Lembaga Studi Islam Assalaam Manado (Siam) Provinsi Sulawesi Utara", h. 86.

Setiadi, Elly M. dkk. Ilmu Sosial dan Budaya Dasar. Cet. V; Jakarta: Kencana Prenada Media Group, 2009.

Simuh, Islam dan Pergumulan Budaya Jawa. Cet. I; Jakarta: Teraju, 2003.

St. Kuraedah, Marlina Ghazali1, dan Pairin, "Analysis of Character Education Values in Pemmali Culture of Bugis Makassar Society", h. 5.

Sulaeman, Munandar. Ilmu Budaya Dasar; Sebuah Pengantar. Cet. VI; Bandung: PT Refika Aditama, 1998

Tahir, Gustia. "Sinergitas Ilmu dan Adab", Jurnal Adabiyah XV, nomor 1 (2015), h. 22-23.

Wahid, Sugira. Manusia Makassar. Cet. II, Makassar, Refleksi, 2008.

Wahyuni. Sosiologi Bugis Makassar. Makassar: Alauddin University Press, 2014.

Yunus, Rasid. "Transformasi Nilai-nilai Budaya Lokal sebagai Upaya Pembangunan Karakter Bangsa", Jurnal Penelitian Pendidikan, Vol. 13, No. 1/2013, h. 67. 